Sawsan H AL-Jubori BDS, MSc ( Lec.)

\section{The Effect of Bleaching on the Color Stabil- ity and Microhardness of Tooth-Colored Restorative Materials}

Department of Conservative Dentistry College of Dentistry, University of Mosul

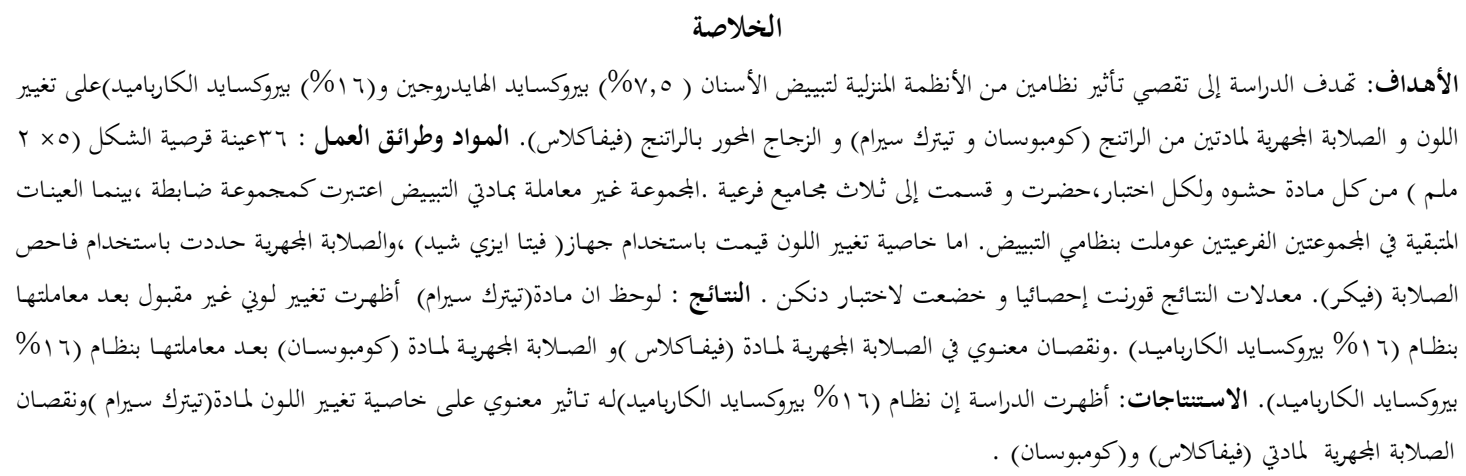

\begin{abstract}
Aims: This study investigated the effect of two home- bleaching regimens $(7.5 \%$ hydrogen peroxide, $16 \%$ carbamide peroxide) on the color change and microhardness of microhybrid composite (Composan) and hybrid composite (TetricCeram) and RMGIC (Vivaglass). Materials and Methods: Thirty six disk - shaped specimens $(5 \times 2 \mathrm{~mm})($ of each restorative material for each test) were prepared and divided into three subgroup $(n=12)$. An unbleached group was used as control, while the remaining specimens in the two subgroups were bleached with bleaching regimens. Color change was assessed by using Vita Easy shade device, and the microhardness was determined by a Vicker's microhardness tester. Means values were compared statistically with one way analysis of variance (ANOVA) followed by Duncan's Multiple Rang Test to determine the significant differences among the tested groups at $(\mathrm{p}$ $=\leq 0.05$ )level of significance. Results: TetricCeram displayed unacceptable color change after bleaching with(16\% carbamide peroxide) bleaching regimen. Decreasing in microhardness of Vivaglass after bleaching regimens, and microhardness of Composan after $16 \%$ carbamide peroxide. Conclusion: The $16 \%$ carbamide peroxide bleaching regimen has significant effects on color change of TetricCeram and decreasing microhardness of Vivaglass and Composan restorative materials.
\end{abstract}

Key words: bleaching, color change, microhardness.

AL-Jubori SH. The Effect of Bleaching on the Color Stability and Microhardness of Tooth-Colored Restorative Materials. Al-Rafidain Dent J. 2013; 13(2): 184-191.

Received: 10/1/2011 Sent to Referees: 11/1/2011

Accepted for Publication: 1/6/2011

\section{INTRODUCTION}

One of reasons for seeking cosmetic dental care is discoloration of the anterior teeth. Even those whose teeth are of normal color often want them whiter. ${ }^{(1)}$ With carful case selection, diagnosis, and treatment planning, bleaching can change a patients smile dramatically. ${ }^{(2)}$ Vital tooth bleaching with peroxide is one of the most common cosmetic procedures to achieve this requirement. ${ }^{(3)}$ Bleaching involves an oxidation process by which the molecules causing discoloration are chemically modified. ${ }^{(4)}$ Oxygenating agents like carbamide peroxide or hydrogen peroxide are used for effective bleaching. The application of these agents is performed in the office by clinicians or at home by patients ultimately resulting in high patient satisfaction. ${ }^{(5-6)}$ The efficacy of bleaching depending on the type of stain, its etiology ${ }^{(7)}$, the duration of the bleaching agent application, and the concentration of the peroxide used. ${ }^{(8)}$ However, these bleaching agents were found to have a profound influence on the color behavior of tooth-colored restorations or perhaps even deteriorate them ${ }^{(9-10)}$. Effects of various bleaching agents on restorative materials may require the replacement of existing restoration for 
esthetic reasons. ${ }^{(11-12)}$ Component systems of different restorative materials such as monomer systems in composites and acid components in glass ionomer cements may show varied responses to bleaching agents. ${ }^{(13)}$

Surface hardness defined as the resistance of the material to indentation or penetration ${ }^{(14)}$, it is related to materials strength, proportional limit and its ability to be abraded by opposing dental structures or materials, any chemical softening resulting from bleaching has implications on the clinical durability of restorations. ${ }^{(15)}$ Studies investigating the effect of bleaching treatments on the microhardness of restorative materials has reported conflicting results. ${ }^{(16-17)}$ The purpose of this in vitro study was to evaluate the effect of two home- bleaching regimens at different concentrations $7.5 \%$ hydrogen peroxide, $16 \%$ carbamide peroxide on color changes and microhardess of three tooth-colored restorative materials .

\section{MATERIALS AND METHODS}

Three clinically used esthetic restorative materials and two home bleaching regimens were selected for this study. The restorative materials were microhybrid composite (A3) (Composan LCM, Promedica, Germany), resin modified glass ionomer cement (Vivaglass, Ivoclar, Vivadent) and hybrid compsite (A3) (TetricCeram, Ivoclar, Vivadent). The bleaching regimens, $7.5 \%$ hydrogen peroxide (Home Peroxide II, D.M.C. Equipamentos LTDA, Brazil) and $16 \%$ carbamide peroxide (Home Peroxide, D.M.C. Equipamentos LTDA, Brazil). For each color and microhardness measurements specimens, a Teflon mold of $5 \mathrm{~mm}$ in diameter and $2 \mathrm{~mm}$ in thickness was used for sample preparations of the restorative materials. ${ }^{(15)}$ This mold was sandwiched between two glass slides. The restorative materials were placed into the mold using plastic instruments. In accordance with the manufacturer's directions, the thickness of the samples built up in $2 \mathrm{~mm}$ increments, light curing according to manufacturer's instructions at $550 \mathrm{mWcm}^{-2}$ using (LEDition, Ivoclar, Vivadent, Germany) light curing unit, with light cure tip is in contact with the sample . Following the light curing, the speci- mens were removed from the molds, polished with medium, fine and superfine disks on the slow speed hand-piece and placed in distilled water for 24 hours to assure complete polymerization. Seventy two specimens of each restorative materials were fabricated (36 for color measurements, 36 for microhardness measurements ), and randomly divided into three groups as follows:

Group 1 : specimens were stored in distilled water at room temp. for two weeks (control).

Group 2: specimens were treated with (Home Peroxide II) bleaching regimen (7.5\% hydrogen peroxide ) on the top surface of each sample for 1 hour per day for two weeks.

Group 3: specimens were treated with (Home Peroxide) bleaching regimen (16\% carbamid peroxide ) on the top surface of each sample for 4 hour per day for two weeks.

The bleaching procedures were performed according manufacturer's instructions. Each day when specimens were removed from the bleach, they were washed in running distilled water with soft brush for $30 \mathrm{~s}$ and placed in fresh distilled water until the next daily treatment. The control specimens were kept in distilled water only.

Color measurements:

By using Vita Easy shade (Vident, North America, USA). the device is worming up, the bottom of screen display a "presets " selection box. Touching "presets" allows Easy shade's default mode of operation to be selected and saved, this is achieved by the touch screen of the device. The appropriate mode of operation was selected and the device is adjusted to display the results of the measurements as L(lightness), C(chroma) and $\mathrm{H}$ (hue) . The device must be calibrated each time when power up, calibration is achieved by placing its probe against a calibration block housed within machine, according to manufacturer's instructions. Five measurements were performed for each specimen, and the mean of the reading was calculated. The measured values of $\mathrm{L}, \mathrm{C}$ and $\mathrm{H}$ for each sample were transformed into baseline $L^{*}, a^{*}, b^{*}$ values .The total color changes is represented by: 
$\left.\left.\mathrm{b}_{1} *\right)^{2}\right]^{1 / 2}$

$\Delta \mathrm{E}=\left[\left(\mathrm{L}_{2} *-\mathrm{L}_{1} *\right)^{2}+\left(\mathrm{a}_{2} *-\mathrm{a}_{1} *\right)^{2}+\left(\mathrm{b}_{2} *-\right.\right.$

Where $\mathrm{L}^{*}$ represent lightness, $\mathrm{a}^{*}$ redness-greenness and $b^{*}$ yellownessblueness ${ }^{(14-18)} . \Delta \mathrm{E} \leq 3.7$ is considered to be clinically acceptable in vitro study. $(3,19,20)$

Microhardness measurements: A Vickers Microhardness tester (Wolpert, West Germany) was used, with a $200 \mathrm{~g}$ load with a dwell time of $15 \mathrm{~s}$, this method depend on visualization of the surface indentations through the microscope of the testing machine. Four indentations were made at random on the top surface of each specimen, and a mean value was calculat- ed. The vicker's hardness is obtained with the following formula ${ }^{(15,21)}$ :

$\mathrm{VH}=1.854 \mathrm{P} / \mathrm{d}^{2}$

Where $\mathrm{P}$ is the applied $\operatorname{load}(\mathrm{Kg}), \mathrm{d}$ is the average length of measured diagonals (mm).

Data were tabulated and statistically analyzed using (ANOVA) following by Duncan's Multiple Rang Test at 5\% level of significance to indicate if there were any statistical differences between groups.

\section{RESULTS}

Analysis of variance (ANOVA) at level 5\% listed in Table (1)

Table (1): ANOVA results for color measurements

\begin{tabular}{|c|c|c|c|c|c|c|c|}
\hline $\begin{array}{l}\text { Restorative } \\
\text { materials }\end{array}$ & & Source of variance & Df & SS & MS & F-Value & Sig. \\
\hline \multirow{9}{*}{ 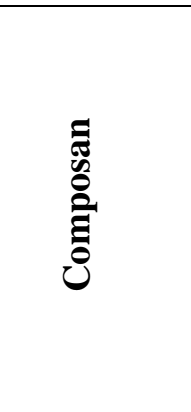 } & \multirow{4}{*}{$\mathrm{L}$} & Between Groups & 2 & 9.360 & 4.680 & 2.316 & .114 \\
\hline & & Within Groups & 33 & 66.680 & 2.021 & & \\
\hline & & Total & 35 & 76.040 & & & \\
\hline & & Between Groups & 2 & 2.462 & 1.231 & .710 & .499 \\
\hline & \multirow[t]{3}{*}{$\mathrm{a}$} & Within Groups & 33 & 57.253 & 1.735 & & \\
\hline & & Total & 35 & 59.716 & & & \\
\hline & & Between Groups & 2 & 3.807 & 1.903 & .077 & .926 \\
\hline & \multirow[t]{3}{*}{ b } & Within Groups & 33 & 812.703 & 24.627 & & \\
\hline & & Total & 35 & 816.510 & & & \\
\hline \multirow{9}{*}{ 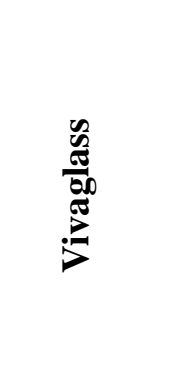 } & & Between Groups & 2 & 15.316 & 7.658 & .266 & .768 \\
\hline & \multirow[t]{3}{*}{$\mathrm{L}$} & Within Groups & 33 & 948.547 & 28.744 & & \\
\hline & & Total & 35 & 963.862 & & & \\
\hline & & Between Groups & 2 & 11.707 & 5.853 & 1.844 & 174 \\
\hline & \multirow[t]{3}{*}{$\mathrm{a}$} & Within Groups & 33 & 104.773 & 3.175 & & \\
\hline & & Total & 35 & 116.480 & & & \\
\hline & & Between Groups & 2 & 2.569 & 1.284 & .194 & .824 \\
\hline & \multirow[t]{3}{*}{ b } & Within Groups & 33 & 217.933 & 6.604 & & \\
\hline & & Total & 35 & 220.502 & & & \\
\hline \multirow{9}{*}{ 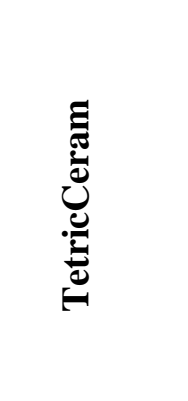 } & & Between Groups & 2 & 151.787 & 75.893 & 18.147 & .000 \\
\hline & \multirow[t]{3}{*}{$\mathrm{L}$} & Within Groups & 33 & 138.013 & 4.182 & & \\
\hline & & Total & 35 & 289.8 & & & \\
\hline & & Between Groups & 2 & 15.369 & 7.684 & 5.832 & .007 \\
\hline & \multirow[t]{2}{*}{ a } & Within Groups & 33 & 43.480 & 1.318 & & \\
\hline & & Total & 35 & 58.849 & & & \\
\hline & \multirow{3}{*}{ b } & Between Groups & 2 & 48.08 & 24.040 & 4.276 & .022 \\
\hline & & Within Groups & 33 & 185.52 & 5.622 & & \\
\hline & & Total & 35 & 233.60 & & & \\
\hline
\end{tabular}

*Significant differences at $p \leq 0.05, \mathrm{~L}$ :lightness, a: redness-greenness and $\mathrm{b}$ : yellowness-blueness. Df: degree of freedom ,SS: sum of squares ,MS: mean square.

Which showed there is no significant differences of $L^{*}, a^{*}, b^{*}$ values of all groups of restorative materials ( Componsan, Vivaglass ) except TetricCeram restorative material which represent the significant differences.Duncan's Multiple Rang Test 
identify statistically the effects of bleaching regimens on $\mathrm{L}^{*} \mathrm{a}^{*}, \mathrm{~b}^{*}$ values restorative

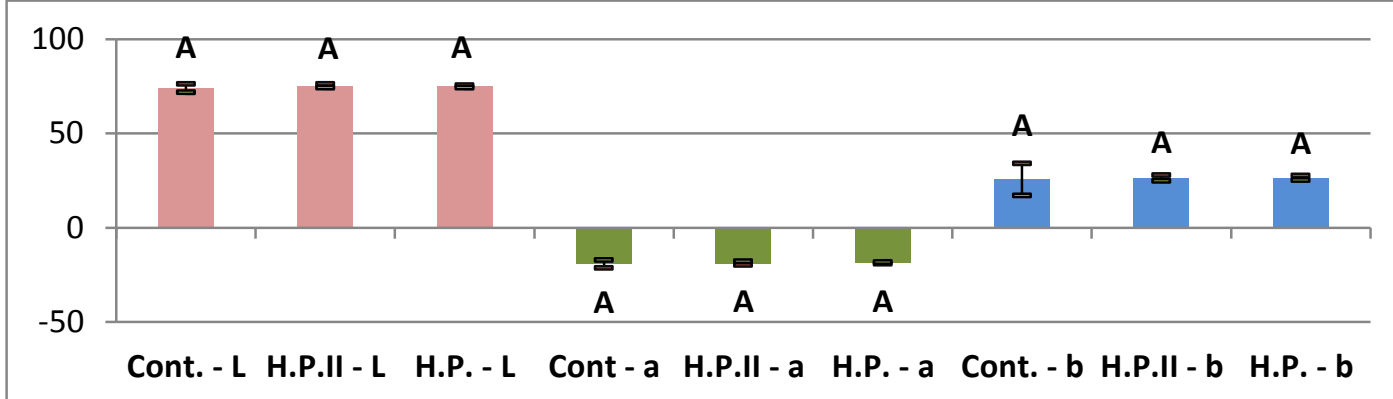

Cont. :control, H.P.II. : $7.5 \%$ hydrogen peroxide, H.P. : $16 \%$ carbamide peroxide $*$ Different letters mean significant differences at $p \leq 0.05$.

Figure (1): Mean \pm SD and Duncan's Multiple Range Test of L*, ${ }^{*}, b^{*}$ for Composan restorative materials.

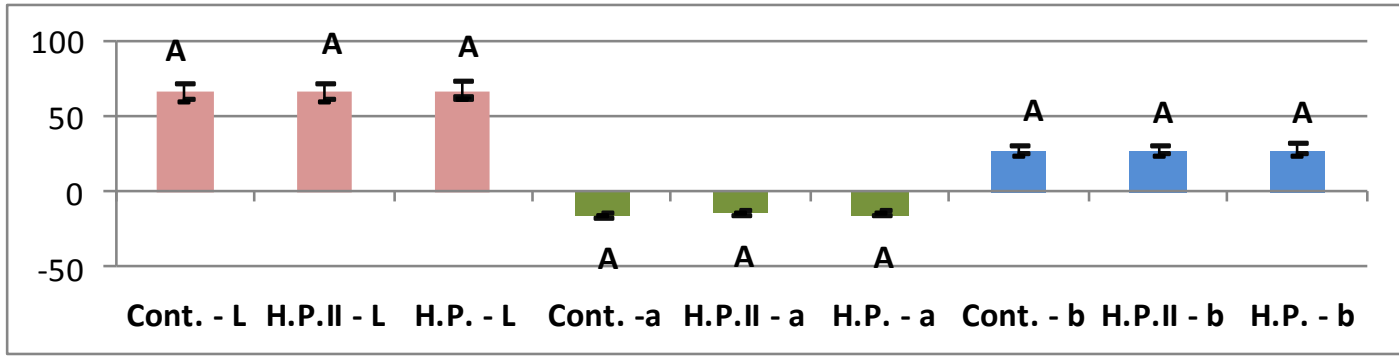

*Different letters mean significant differences at $p \leq 0.05$.

Figure (2): Mean \pm SD and Duncan's Multiple Range Test of $L^{*}, a^{*}, b^{*}$ for Vivaglass restorative materials.

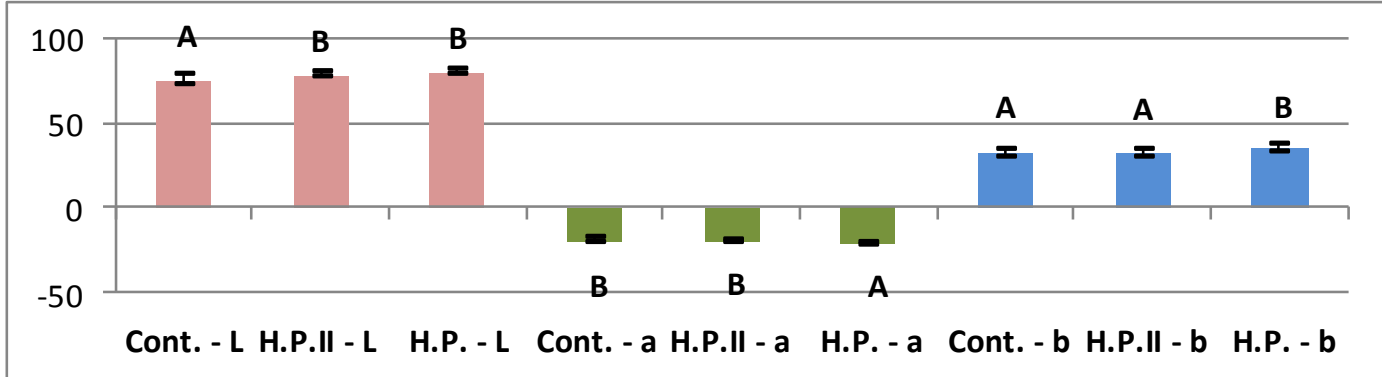

$*$ Different letters mean significant differences at $p \leq 0.05$.

Figure (3): Mean \pm SD and Duncan's Multiple Range Test of $L^{*}, a^{*}, b^{*}$ for TetricCeram restorative materials.

For Composan, Vivaglass, TetricCeram restorative material respectively, which indicated that, there is significant increasing of $L^{*}, a^{*}, b^{*}$ values of TetricCeram after bleaching with $16 \%$ carbamid peroxide bleaching regimen, which produce unacceptable color change according to $\left(\mathrm{CIE} \mathrm{L} \mathrm{a}^{*} \mathrm{~b}^{*}\right)$ color $\operatorname{system}(\Delta \mathrm{E}=5.648)$ Table (2) 
Table (2): Total color changes in (CIE L*a*b*) color system for bleaching groups of restorative materials.

\begin{tabular}{lcccc}
\hline & \multicolumn{2}{c}{ Groups } & $\Delta \mathbf{E}$ & In Vitro \\
\hline Cont.Comp. & vs & H.P.II.Comp. & 1.488 & Accepted \\
Cont.Comp. & vs & H.P. Comp. & 1.216 & Accepted \\
Cont.Vivag. & vs & H.P.II. Vivag. & 1.489 & Accepted \\
Cont.Vivag. & vs & H.P. Vivag. & 1.655 & Accepted \\
Cont.Tetric. & vs & H.P.II. Tetric. & 3.570 & Accepted \\
Cont.Tetric. & vs & H.P. Tetric & 5.648 & Not
\end{tabular}

Cont. :control, comp. : composan, H.P.II. : 7.5\% hydrogen peroxide, H.P. : $16 \%$ carbamide peroxide, Vivag. :Vivaglass, Tetric. :TetricCeram. $\Delta \mathrm{E} \leq 3.7$ Changes in color accepted in vitro.

While there is increase in $\mathrm{L}^{*}$ value only after bleaching with $7.5 \%$ hydrogen peroxide. The results displayed that TetricCeram gave high $\Delta \mathrm{E}$ after bleaching. Analy- sis of variance (ANOVA) at level 5\% for Vickers hardness measurements listed in Table (3).

Table (3): ANOVA results for Vickers hardness values(VHN) measurements.

\begin{tabular}{|c|c|c|c|c|c|c|}
\hline $\begin{array}{c}\text { Restorative materi- } \\
\text { als }\end{array}$ & $\begin{array}{l}\text { Source of vari- } \\
\text { ance }\end{array}$ & Df & SS & MS & F-Value & Sig. \\
\hline \multirow{3}{*}{ Composan } & Between Groups & 2 & 770.348 & 385.174 & 5.507 & .009 \\
\hline & Within Groups & 33 & 2307.969 & 69.938 & & \\
\hline & Total & 35 & 3078.316 & & & \\
\hline \multirow{3}{*}{ Vivaglass } & Between Groups & 2 & 1302.101 & 651.051 & 12.915 & .000 \\
\hline & Within Groups & 33 & 1663.588 & 50.412 & & \\
\hline & Total & 35 & 2965.689 & & & \\
\hline \multirow{3}{*}{ TetricCeram } & Between Groups & 2 & 3.372 & 1.686 & 139 & .870 \\
\hline & Within Groups & 33 & 398.872 & 12.087 & & \\
\hline & Total & 35 & 402.244 & & & \\
\hline
\end{tabular}

*Significant differences at $p \leq 0.05$.

Which indicated that there is significant differences in microhardness of Composan and Vivaglass restorative materials after bleaching procedure. Duncan's Mul- tiple Rang Test (Figure 4) identified that There is decreasing in microhardness of Vivaglass and (H.P. comp. ) group after bleaching procedures.

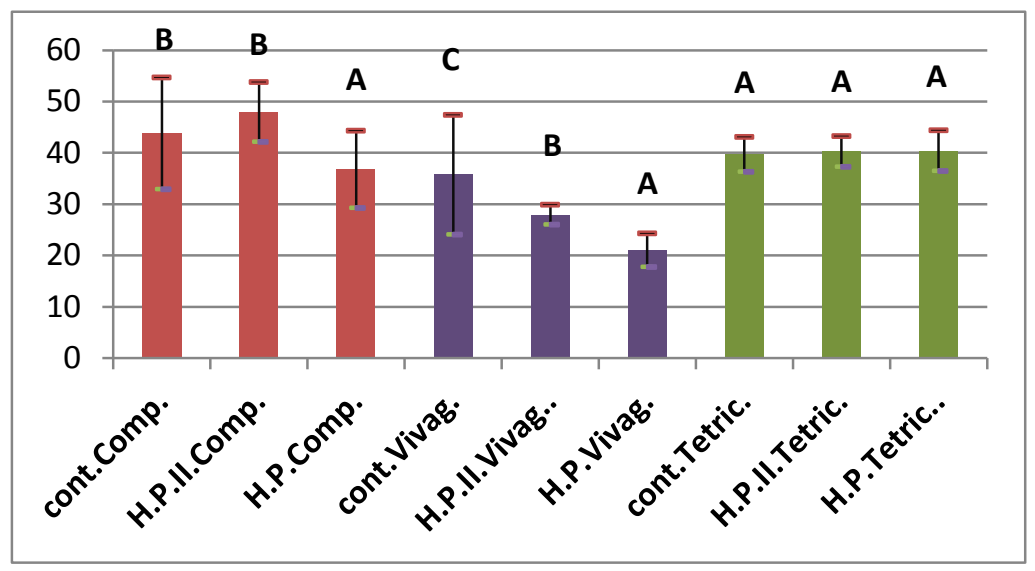

*Different letters mean significant differences at $\mathrm{p} \leq 0.05$.

Figure (4): Mean \pm SD and Duncan's Multiple Range Test of microhardness for restorative materials. 


\section{DISCUSSION}

The bleaching agents may have a varying influence on the restorative materials and may even deteriorate them. Materials with different monomer systems, such as composites and RMGIC may show varying response to bleaching agents, estimation of hardness may indicate deteriorating effects on the restorative materials ${ }^{(16)}$.

The results of this in vitro study indicated that there is no significant differences in $\mathrm{L}^{*}, a^{*}, b^{*}$ values of color measurements of all bleaching groups except TetricCeram produced unacceptable color change after bleaching with $16 \%$ carbamide peroxide this may be attributed to the amount of resin and its component which is the source of discoloration, filler particles and to greater volume fractions of resin matrix ${ }^{(22)}$. Alterations in color have been attributed to oxidation of surface pigments and amine compounds, which have also be indicated as responsible for color instability of restorative materials over time ${ }^{(5)}$.Differences in color change between different materials might be a result of different amount of the resin and different degrees of conversion of the resin matrix to polymer ${ }^{(23)}$. Differences in the bleaching effect of the agents on the same materials might be related to their different hydrogen peroxide contents, so the higher efficacy due to an excess of active ingredient that readily diffused ${ }^{(8)}$. The non significant results coincide with the result of Kim et al ${ }^{(24)}$ the influence of tooth whitening film and strip on the color of dental composite is negligible. Other studies ${ }^{(25-26)}$ indicated that color change of plastic restorative materials bleaching during is both filling material and bleach specific.

There is controversy about the effect of bleaching agents on surface microhardness of restorative composite materials. In some investigations softening of composite resins was associated with the application of home-bleaching gels ${ }^{(27-28)}$,other investigation's revealed no significant hardness changes ${ }^{(29-31)}$,or even increase in surface hardness ${ }^{(2,17)}$, such wide variation in data suggest that some tooth colored restorative materials may by more susceptible to alteration and some bleaching agents are more likely to cause those alter- ation ${ }^{(32-33)}$. Our study agreement with Gurgan and Yalcin ${ }^{(29)}$ and Polydorou et$\mathrm{al}^{(31)}$, which reported that the bleaching agents $(6 \%-15 \%)$ did not significantly alter the microhardness of composite restoration .

The significant decrease of micro hardness of Vivaglass agreed with Hassan and Fahmy ${ }^{(34)}$ which indicated that the decrease of micro hardness can be attributed to the alteration of atomic weight percentage in RMGIC and the matrix of the specimens showed surface wash -off and corrosion with the cores of silica more exposed and decrease of surface aluminum content .And not agreed with Polydorou et al ${ }^{(31)}$ which reported that the micro hardness of RMGIC remain stable after bleaching with $10-16 \%$ carbamide peroxide bleaching agents .

The reduction of microhardness of Composan after bleaching with16\% carbamide peroxide, it may attributed to the negative influence of oxidation agents of bleaching agent on the resin matrix led to water uptake of the restorative materials with complete or partial debonding of fillers causing reduced surface integrity and loss of hardness of the materials ${ }^{(5)}$.

\section{CONCLUSION}

Within the limitation of this in vitro study the following conclusions were drawn:

1- TetricCeram display unacceptable total color change after bleaching with $16 \%$ carbamide peroxide.

2- Decreasing in microhardness of Composan after bleaching with $16 \%$ carbamide peroxide bleaching regimen.

3- After two home - bleaching regimens there is decreasing in microhardness of Vivaglass.

\section{REFERENCES}

1. Dahl J E, Pallesen U .Tooth bleaching -A critical review of the biological aspects . $J$ Crit Rev Oral Biol Med .2003;14(4) :292 304 .

2. Türker SB, Biskin T. Effect of three bleaching agents on the surface properties of three different esthetic restorative materials . J Prosthet Dent. 2003; 89(5): 466 473 . 
3. Johnston WM, Kao EC. Assessment of appearance match by visual observation and clinical colorimetry. $J$ Dent Res.1989;68(5):819-822.

4. Matis BA, Yousef M, Cochran MA, Eckert GJ. Degradation of bleaching gels in vivo as a function of tray design and carbamide peroxide concentration .Oper Dent. 2002; 27: $12-8$.

5. Attin T, Hannig C, Wiegand A, Attin R .Effect of bleaching on restorative materials and restoration - a systemic review .Dent Mat. 2004;20(9):852 - 861.

6. Ayad NM .The effect of a current home bleaching agent on the color of nine tooth - colored restorative materials stained with common beverages :An in vitro study .Internet J Dent Science.2009;6(2) ISSN 1937 - 8238.

7. Rodrigues JA, Pimenta LA .Microhardness evaluation of in situ vital bleaching on human enamel using a novel study design . Dent Mat .2005;21:1059 - 1067.

8. Hubbezoglu I, Akaoglu B, Dogan A, Keskin S, Bolayir G, Özceuk S, Dogan OM .Effect of bleaching on color change and refractive index of dental composite resins . Dent Mat. 2008;27(1):105 - 116.

9. Vieira GF, Arakaki Y, Caneppele TMF .Spectrophotometric assessment of the effects of $10 \%$ carbamide peroxide on enamel translucency. Braz Oral Res. 2008;22(1):90 - 95.

10. Braun A, Jepsen S, Krause F. Spectrophotometric and visual evaluation of vital tooth bleaching employing different carbamide peroxide concentrations. J Dent Mat.2007;23(ISSN 2):165 - 169.

11. Mokhlis GH, Matis BA, Cochran MA, Eckert GJ .A clinical evaluation of carbamide peroxide whitening agents during daytime use. $J$ Am Dent Assoc $.2000 ; 131: 1269-1277$.

12. Ahmad KI, Sajjan G. Color stability of ionomer and resin composite restoratives in various environmental solutions an in vitro reflection spectrophotometric study .J Conser Dent .2005;(8)1:45 - 51.

13. Liad Q, Yubd H, Wangc Y. Color and surface analysis of carbamide peroxide bleaching effects on the dental restorative materials in situ. J Dent .2009;37(5):348 356.

14. Craig RG, Powers JM ( 2002). Restorative Dental Materials, $11^{\text {th }}$ ed, CV Mosby
Company,pp.41.

15. Bayindir F, Colak KM, Uzun IH .Effect of tooth whitener on microhardness of tooth color restorative materials .J Mater Res Innov. 2009;13(1):28 - 31.

16. Parbhaker AR, Sahana S, Mohantesh T, Vishwas TD . Effect of different concentrations of bleaching agent on the microhardness and shear bond strength of restorative materials - An in vitro study . $J$ Dent Oral Hygien. 2010;2(1):7 - 14.

17. Compos I, Briso ALF, Pimenta LAF, Ambrosano G. Effects of bleaching with carbamide peroxide gels on microhardness of restorative materials .J Esthet Restor Dent. 2003;15(3):175 - 83 .

18. Recommendations on uniform color spaces. Color differences equations . psychometric color terms. Supplement No.2 to CIE publication No.15(E - 13.1) 1971 /TC - 1.3), Paris: Burean central de al CIE.1978.

19. O'Brien WJ, Grott CL, Boenke KM .Anew small - color - differences equation for dental shades .J Dent Res. 1990;69(11): 1762 - 1764.

20. Wee AG, Lindsey DT, Kuo Sh, Johnston WM .Color accuracy of commercial digital cameras for use in dentistry .Dent mat. 2006;22(6):553 - 559 .

21. Grajower R, Hirschfeld Z, Zalkind M .Observations on cavity liners for composite resin restorations .J Prosthet Dent. 1976;36:256 - 273 .

22. Monaghan P, Trowbridge T, Lautenschlager E .Composite resin color- change after vital tooth bleaching. J Prosthet Dent.1992;67:778 - 81.

23. Rao MY, Srilakshmi V, Vinayagam KK, Narayagan LL .An evaluation of the color stability of tooth-colored restorative materials after bleaching using CIELAB color technique .Indian $J$ Dent Res. 2009;20(1):60 - 64 .

24. Kim JH, Lee YK, Lim BS, Rhee SH, Yang HC .Effect of tooth whitening strips and films on changes in color and surface roughness of resin composites .Clinc Oral Invest .2004;8(3):118 - 122 .

25. Canay S, Cehreli MC .The effect of current bleaching agents on the color of light-polymerized composites in vitro. $J$ Prosthet Dent. 2003; 89(5):474 - 478.

26. Yalcin F, Gurgan S .Bleaching-induced color change in plastic filling materials.$J$ 
Biomat Appl.2005;19(3):187 - 195.

27. Bailey SJ, Swift EJ .Effect of home bleaching products on composite resins .Quint Inter .1992;23(7):489 - 494.

28. Türker SB, Biskin $\mathrm{T}$. The effect of bleaching agents on the micro hardness of dental esthetic restorative materials .J Oral Rehabil .2002;29(7):657 - 661.

29. Gurgan S, Yalcin F . The effect of different bleaching regimens on the surface roughness and hardness of tooth-colored restorative materials .J Quint Inter $.2007 ; 38(2): 83-87$.

30. Mujdeci A, Gokay O .Effect of bleaching agents on the micro hardness of toothcolored restorative materials .J Prosthet Dent .2006;95(4):286 - 9.

31. Polydorou O, Hellwig E, Auschill Th M. The effect of at-home bleaching on the microhardness of six esthetic restorative materials. J Amer Dent Assoc. 2007; 138(7): $978-84$.

32. Costa SXS, Becker AB, Rastelli ANS . Effect of four bleaching regimens on color changes and microhardness of dental nanofilled composite .Inter J Dent. 2009; 2009: 1 - 7 .

33. Taher NM . The effect of bleaching agents on the surface hardness of toothcolored restorative materials .J Contemp Dent Pract .2005;6(2):18 - 26.

34. Hassan MAM, Fahmy OMI .Microhardness and surface texture assessment of three direct esthetic restorative materials following application of a home bleaching agents. Cairo Dent $J$. 1999;15(1): 495 - 498 . 